\section{The Maxillary Neurovascular Canals as the Basis for the Local Anesthesia Efficacy}

\section{Abstract}

It is not known the way in which a local anesthetic, following the Anterior Middle Superior Alveolar (AMSA) anesthesia, reaches the superior dental plexus. Consequently, the aim of the study was to examine the possible route of diffusion of a local anesthetic from the anterior lateral palatal injection to the superior dental plexus. The palatal and alveolar regions of 48 dry maxillae were examined and 6 autopsy specimens of the same region were prepared for histological and immunohistochemical analysis. The study revealed palatal and alveolar process openings in all the specimens. They average 6.3 in number close to the central incisor, 5.2 to the lateral incisor, 3.7 to the canine, 3.8 to the 1 st premolar, and 3.9 to the 2 nd premolar. The microscopic structure of the epithelium, lamina propria, submucous layer, arteries and nerves, periosteum, and cortical and spongious bone was described in detail. The neurovascular pores and canals had a diameter of their opening of $90.28-1,230.62 \mu \mathrm{m}$ (mean, $893.62 \mu \mathrm{m}$ ). The initial part of the canals varied in diameter between $523.42 \mu \mathrm{m}$ and $903.04 \mu \mathrm{m}$ (mean, $622.93 \mu \mathrm{m}$ ). The canals penetrated the cortical bone and usually terminated in the spongious bone towards the alveolar process. They contained a larger artery or several smaller arteries, some veins, a few tiny nerves, collagen fibers type I, and small collections of the fatty cells. The neurovascular canals and the pores most likely represent a route for diffusion of an anesthetic from the lateral palatal region to the superior dental plexus.

Keywords: Neurovascular canals; Maxilla; Anterior teeth; Anatomy; Histology; Local anesthesia

Received: November 07, 2018; Accepted: December 12, 2018; Published: December 19, 2018

\section{Introduction}

One of the procedures in dentistry is the AMSA (Anterior Middle Superior Alveolar) anesthesia, a relatively new local anesthetic technique, which has been introduced to achieve the pulpal anesthesia of the maxillary anterior teeth, and the surrounding tissues, by a single injection of certain anesthetic agent [1-9]. The local anesthetic, applied into the lateral palatal region at the level between the 1st and 2 nd premolar, must diffuse all the way from the injection site to the anterior and middle part of the superior dental plexus, located just above the maxillary teeth roots, and to inhibit there the nociceptive neurotransmission along its dental (pulpal), and gingival and osseous twigs [10-13].

However, there are no precise data in contemporary literature which could explain in which way an anesthetic can penetrate the osseous palatine and alveolar processes of the maxilla,
Dejan Ćetković1, Vera Todorović ${ }^{2,3,4}$, Slobodan Marinkovićc ${ }^{*}$, Harun Hodžićs ${ }^{5}$, Mirza Oruč ${ }^{6}$ and Jelena Boljanović ${ }^{7}$

1 Institute of Anatomy, Faculty of Dental Medicine, University of Belgrade, 11000 Belgrade, Serbia

2 Department of Basic and Preclinical Studies, Faculty of Dentistry, 26000 Pančevo, University of Business Academy, Novi Sad, Serbia

3 Departrment of Histology and Embriology, Faculty of Medicine, University of Zenica, 72000 Zenica, Bosnia and Herzegovina

4 Department of Nursing, Faculty of Medicine, University of Zenica, 72000 Zenica, Bosnia and Herzegovina

5 Department of Neuroanatomy, Faculty of Medicine, Institute of Anatomy, University of Belgrade, 11000 Belgrade, Serbia

6 Department of Surgery, Faculty of Medicine, University of Zenica, 72000 Zenica, Bosnia and Herzegovina

7 Faculty of Special Education and Rehabilitation, University of Belgrade, 11000 Belgrade, Serbia

*Corresponding author:

Dr. Slobodan Marinković

= slobodan.marinkovic@med.bg.ac.rs

Department of Neuroanatomy, Faculty of Medicine, Institute of Anatomy, University of Belgrade, 11000 Belgrade, Serbia.

Tel: 00381644866829

Citation: Ćetković D, Todorović V, Marinković S, Hodžić H, Oruč M, et al. (2018) The Maxillary Neurovascular Canals as the Basis for the Local Anesthesia Efficacy. J Orthod Endod Vol.4 No.4:15 
especially their cortical bone which virtually does not allow a liquid resorption [13]. The only possibility is that an anesthetic uses the neurovascular (nutritive) bony canals to reach the mentioned parts of the superior dental plexus within the upper portion of the alveolar process of the maxilla $[3,11,12]$. To our knowledge, the anatomic and histological examination of these canals has never been performed.

Accordingly, the aim of our study was to find those canals close to the site of the anesthetic injection and the adjacent region, to examine in detail their distribution, structure and contents, as well as to perform certain morphometric study.

\section{Materials and Methods}

This study has two domains, an anatomic, and a histochemical and immunohistochemical examination.

\section{Anatomic observation}

We examined 48 dry maxillae from the collection of the Institute of Anatomy, Faculty of Medicine in Belgrade, with permission of the Institute authorities. In those specimens, the osseous pores and foramina were inspected at the level of the incisors, the canines, and the 1 st and 2 nd premolars by using magnifying glasses $(\times 2$ and $\times 4)$. They were examined from the level of the greater palatine groove toward the sockets of the mentioned maxillary anterior teeth. The location and number of these bony openings were determined. The largest foramina were measured by using a digital caliper (Mitutoyo, Kawasaki, Japan). The minimum, maximum and mean values were counted.

\section{Histochemical processing and staining}

Six specimens of the maxillary region, which included palatine process, alveolar process, palatal mucosa and submucosa, alveolar mucosa and gingiva, were taken during routine autopsy from 3 males and 3 females aged between 54 and 68 years (mean, 59 years). This was approved by the authorities of the Institute of Pathology, Faculty of Medicine in Belgrade, and the Ethical Committee of the Clinical Center of Serbia in Belgrade. We were allowed to use only the unendentous portions of the maxilla and surrounding tissues. Each specimen was cut out from the maxilla by means of a dentist electric drill. Two transverse (coronal) incisions in the oral cavity were made anterior and posterior to the 1st and 2nd premolars, to the level of the middle part of the alveolar process, i.e. just lateral to its palataine (lingual) cortical plate. Then, a sagittal section was placed through the medial part of the hard palate, and another one through the alveolar process. Each cut off specimen measured $11 \times 19 \mathrm{~mm}$ on average.

Tissue samples were fixed in buffered $10 \%$ formaldehyde solution $(\mathrm{pH} 7.5)$ for $48 \mathrm{~h}$, decalcified in a solution of ethylenediaminetetraacetic acid disodium salt -EDTA $[5.5 \mathrm{~g}$, distilled water $90 \mathrm{ml}$, and $10 \mathrm{~mL}$ formaldehyde (37/40\% stock)] for 3 weeks, and finally routinely processed to the paraffin blocks. The samples were prepared for the optic microscopy according to the previously described protocol [14]. Semithin serial sections (6 $\mu \mathrm{m}$ thick) were cut on a rotatory Leica RM2255 microtome (Leica Micro-Systems, Reuil-Malmaison, France), and then adhered to "Super frost" microscopic slides (Menzel-Glaser, Germany). Tissue sections were stained with hematoxylin and eosin (H\&E) and Azan trichrome stain (Bio Optica, Code 04-001802).

Microscopic and morphometric analyses were performed on Olympus BX-41 light microscope, and microphotographs were taken with Olympus XC50 digital camera, using the Cell Sens Entry software (Olympus, Tokyo, Japan).

\section{Immunohistochemical staining}

The immunohistochemical (IHC) method was used for the identification of collagen type I and laminin antigens, which were prepared according to a standard technique [15]. After tissue deparaffinization and rehydration, antigen retrieval was performed by incubating the tissue sections in $0.01 \mathrm{M}$ citrate buffer ( $\mathrm{pH}$ 6.0) in a microwave oven for 20 minutes. Endogenous peroxidase activity was blocked with $0.3 \%$ hydrogen peroxide in methanol for 10 minutes at room temperature. Thereafter, tissue sections were incubated with anti-collagen I (ab34710, Abcam; diluted 1:100 with Dako antibody diluent, Code S0809) or anti-laminin (ab11575, Abcam; diluted 1:400 with Dako antibody diluent, Code S0809) antibodies. The incubation of the tissue samples with primary antibodies was performed overnight at $4^{\circ} \mathrm{C}$. The sections were subsequently treated by applying the commercial UltraVision/DAB staining kit (ThermoScientific LabVision TL-060-HD). Antigen-antibody complexes were visualized with 3,3'-diamino-benzidine (DAB) substrate solution. The sections were counterstained with Mayer's hematoxylin. Negative controls were performed on tissue sections using the same methodology, but with the omission of primary antibody.

\section{Results}

The anatomic examination was first performed, and then the histochemical and the IHC analysis of the post-mortem specimens of the lateral maxillary region.

\section{Anatomic examination}

The anatomic study was undertaken in the lateral palatine region, i.e. just lateral to the greater palatine groove, as well as in the mesial portion of the alveolar process (Figure 1). Both areas were located at the level of the anterior teeth, that is, the central and lateral incisors, and the canine, as well as the 1th and 2nd premolars, where the anesthetic is commonly applied in dental practice.

The examination revealed 1102 total number of the bony openings in 48 dry maxillae. They were presented at the level of the corresponding teeth, where they ranged from 1 to 10 in number (Table 1). Most of the observed openings were small, less than $1 \mathrm{~mm}$ in diameter. In two cases, however, a larger foramen was observed which measured $1.7 \mathrm{~mm}$ and $2.3 \mathrm{~mm}$ in size, respectively (Figure 1). Some of the openings were more or less distant among themselves, whilst some others were grouped at the level of certain teeth (Figure 1).

\section{General histological remarks}

The 827 obtained slices of the lateral palate and the superior 


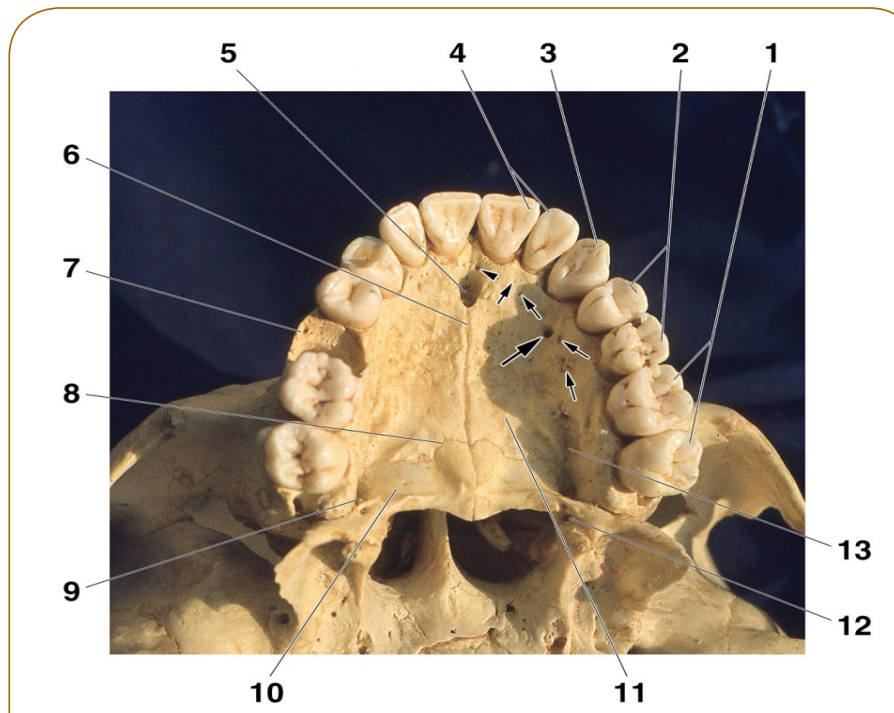

Figure 1 Inferior aspect of the bony palate and the right and left alveolar processes. Note molar teeth (1), premolar teeth (2), canine tooth (3), lateral and central incisors (4), incisive fossa (5), median palatine suture (6), socket for the $2^{\text {nd }}$ premolar (7), transverse palatal suture (8), greater palatine foramen (9), horizontal plate of the palatine bone (10), palatine process of the maxilla (11), lesser palatine foramen (12), and greater palatine groove (13). Also note a larger palatal foramen (larger arrow), several small foramina (smaller arrows), and an opening (arrowhead) close to the incisive fossa and the central incisor.

Table 1 The location and number of the neurovascular openings.

\begin{tabular}{|c|c|}
\hline Level of location & Number: range (mean) \\
\hline Central incisor & $1-10(6.3)$ \\
\hline Lateral incisor & $1-9 \quad(5.2)$ \\
\hline Canine & $1-9$ (3.7) \\
\hline First premolar & $1-7 \quad(3.8)$ \\
\hline Second premolar & $1-7$ (3.9) \\
\hline
\end{tabular}

part of the alveolar process, with surrounding soft tissues (Figure 2), were carefully analyzed. The examination first comprised the mucous membrane and gingiva, including the epithelium and the palatal submucous layer, as well as the periosteum, the bony tissue, and the neurovascular canals and the osseous pores (Figures $\mathbf{2}$ and $\mathbf{3}$ ).

The alveolar gingiva was covered with a stratified squamous epithelium, which is either fully or partially keratinized (Figure 3). The epithelium ranged between $408.03 \mu \mathrm{m}$ and $443.35 \mu \mathrm{m}$ (mean, $430.02 \mu \mathrm{m}$ ) in thickness. The subepithelial layer was made up of a dense irregular connective tissue, with a large number of the collagen fiber bundles. The entire gingiva varied in thickness from $1,593.18 \mu \mathrm{m}$ to $1,799.62 \mu \mathrm{m}$, with a mean value of $1,712.85$ $\mu \mathrm{m}$ (i.e. about $1.7 \mathrm{~mm}$ ).

The alveolar bone showed a superficial cortical (compact) layer composed of a few parallel lamellae. Its deeper and much larger part was made up of the spongy bone with certain spicules and branching trabeculae built by some irregular lamellae (Figure 3). The intertrabecular spaces contained fat cells, small number of collagen fibers, a small amount of the red bone marrow, and tiny blood vessels and nerves sporadically.

The palatal mucosa (Figure 4) was also covered by a stratified squamous epithelium, which was either ortokeratinized or parakeratinized. It ranged in thickness from $536.13 \mu \mathrm{m}$ to 612.75 $\mu \mathrm{m}$ (592.26 $\mu \mathrm{m}$ on average). The thickness of the entire mucous membrane, including both the epithelium and the subepithelial layer, varied between 2,267.55 $\mu \mathrm{m}$ to $3,148.24 \mu \mathrm{m}$ (mean, $2,875.26 \mu \mathrm{m}$, i.e. about $2.87 \mathrm{~mm}$ ). The subepithelial layer, that is, the lamina propria, contained densely packed bundles of collagen fibers (Figure 4).

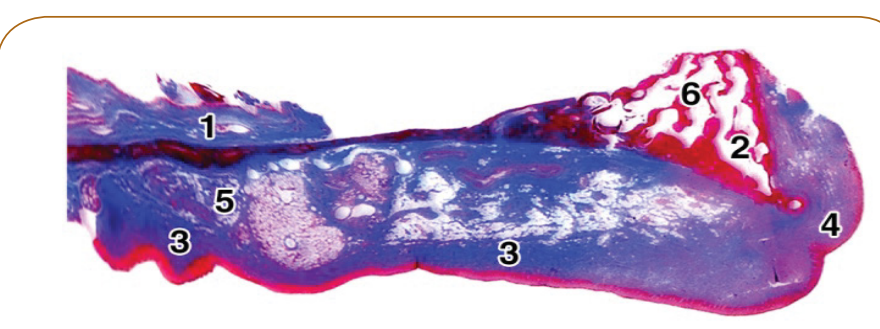

Figure 2 Transverse (coronal) section of the left lateral palatal region (1) and the upper part of the alveolar mucous membrane (4), submucous layer with minor salivary glands, arteries and nerves (5), and spongious bone (6). Also note the nasal mucosa above the medial part of the palatine process. ( $\times 2$, Azan trichrome staining).

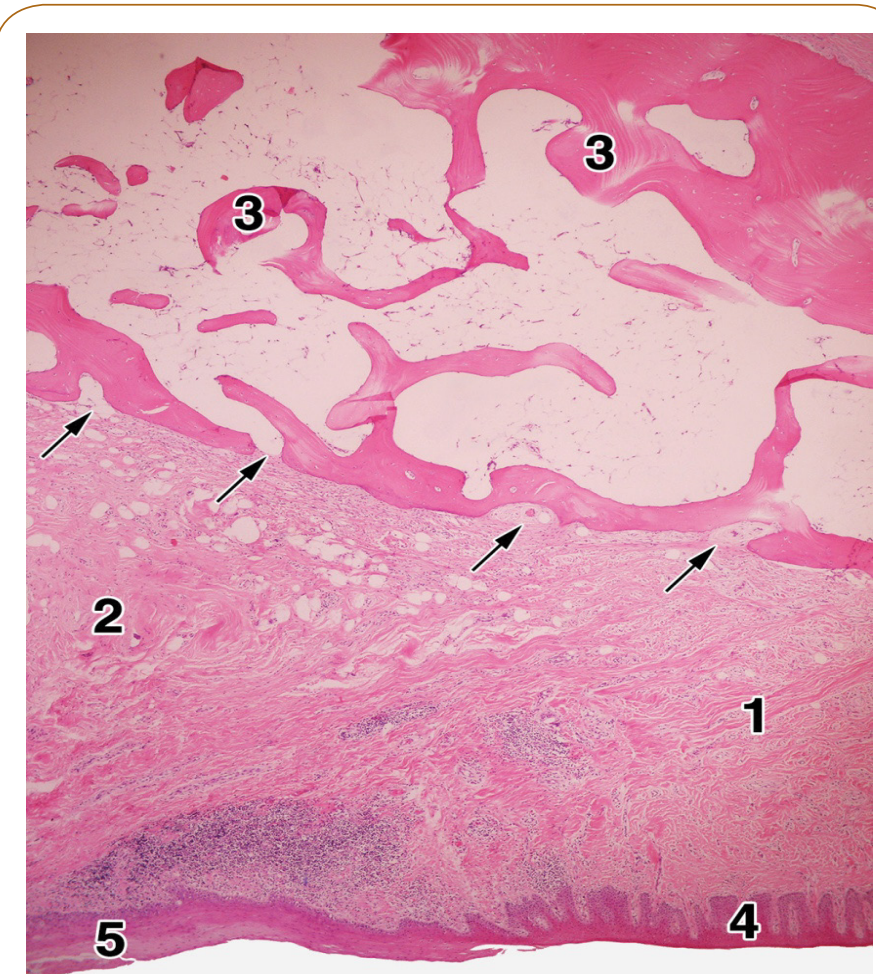

Figure 3 Transverse section of the gingiva (1) and the mucosa (2) of the alveolar process with its spongious bone (3). Note gingival epithelium (4), epithelium of the alveolar mucosa (5), and small pores of the alveolar bone (arrows). ( $\times 4, \mathrm{H} \&$ E staining). 


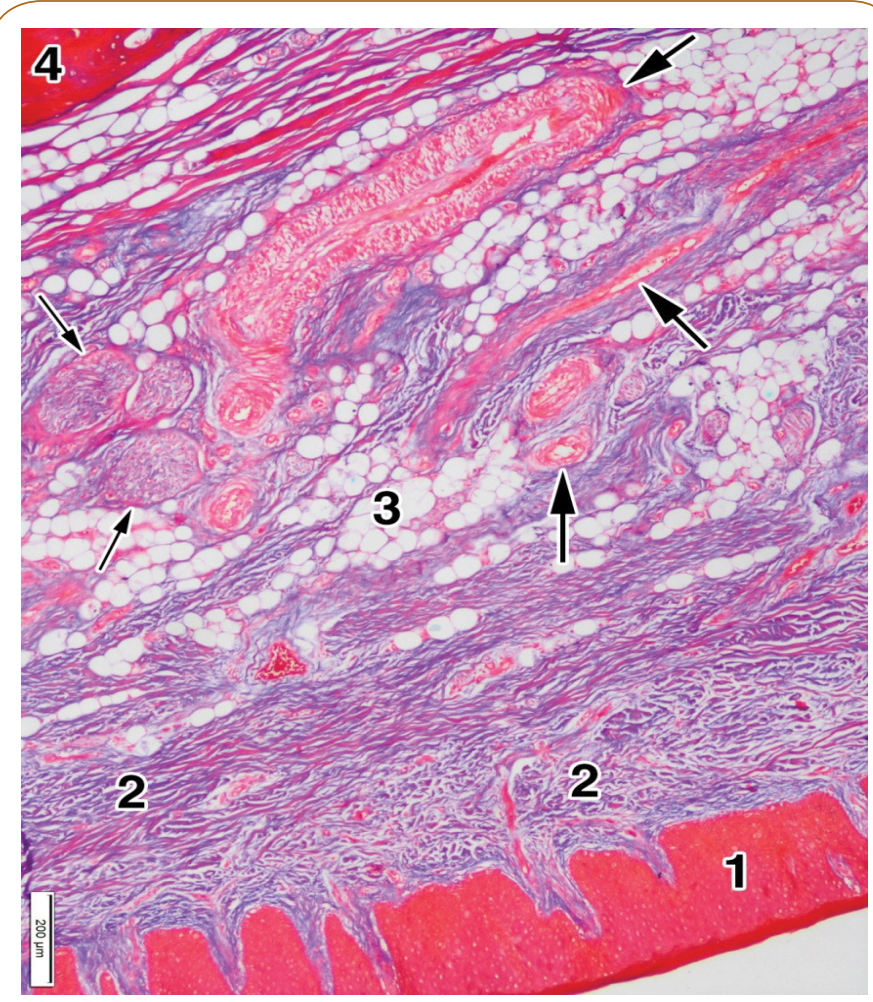

Figure 4 Palatal epithelium (1) and the subepithelial collagen fibers (2). Note fat cells (3), cortical bone of the palatine process (4), the submucous palatal arteries (larger arrows) and nerves (smaller arrows). Also note a measuring bar in the left bottom corner. (Azan trichrome staining).

The submucous layer contained collagen fibers as well, but also the fat tissue, salivary glands (Figure 2), blood vessels, and nerves (Figure 4). The collagen fibers were present throughout this layer in a smaller or larger amount. The smaller or larger collections of the fat cells (adipocytes) were randomly arranged within the submucous layer among the collagen fiber bundles, and around the blood vessels and nerves (Figure 4). They showed a typical appearance: round or polygonal in shape, with a lucent cytoplasm and small, dark and elongated nucleus at the periphery.

The minor salivary glands were present within the submucous layer at the level of the 1st and 2nd premolars (Figure 2). Their main cells contained small secretory granules and a dark nucleus located in their basal part. The cone-shaped and tightly packed cells were oriented toward the central part of each acinus.

The blood vessels were abundant within the submucous layer (Figure 4). The arteries were more often seen than the veins, and they represented the branches of the greater palatine artery. Their wall consisted of the intima, media, and adventitial coats, with a clearly visible internal elastic lamina.

The nerves of smaller or larger size were observed among the collagen bundles and often close to the blood vessels (Figure 4). They contained densely packed axons with the Schwann cells surrounded by the perineurium. All of them were branches of the greater palatine nerve.

The palatine process showed the periosteum, and the cortical and spongy bone (Figure 5). The periosteum presented as a thin connective layer covering the surface of the palatine process. It contained densely packed collagen bundles with a relatively large number of the smaller blood vessels (Figure 4). The periosteum ranged in thickness from $87.59 \mu \mathrm{m}$ to $121.67 \mu \mathrm{m}$ (mean, $106.69 \mu \mathrm{m}$ ).

The cortical bone comprised the most superficial layer of the palatine process, to which the periosteum was attached (Figures 4 and 5). It consisted of only a few parallel osseous lamellae (Figure 5). Just above that thin layer, the osteons were located close to each other (Figure 5). They were formed by the concentric lamellae, ranging in number from 4 to 12 (7.14 on average). The lamellae contained the osteocytes embedded within their lacunae. A Haversian canal was present in the center of each osteon (Figure 5). The osteons varied in size between $311.02 \mu \mathrm{m}$ to $869.16 \mu \mathrm{m}$ (mean, $667.80 \mu \mathrm{m}$ ). The Haversian canals ranged in diameter from $114.23 \mu \mathrm{m}$ to $347.82 \mu \mathrm{m}$ ( $231.23 \mu \mathrm{m}$ on average). They mainly contained small blood vessels and tiny nerves. After decalcification, the concentric lamellae of Haversian osteons moderately expressed collagen type I.

\section{Neurovascular canals}

We examined first some small openings of the cortical bone of the alveolar and palatine processes, and then true osseous canals in histological slices.

The upper mesial part of the alveolar process of each histological specimen contained between 3 and 6 pores (mean, 4.2). They were isolated or grouped, in the latter case comprising sometimes 3 or 4 of them in a microscopic field (Figure 3 ). Some of the pores

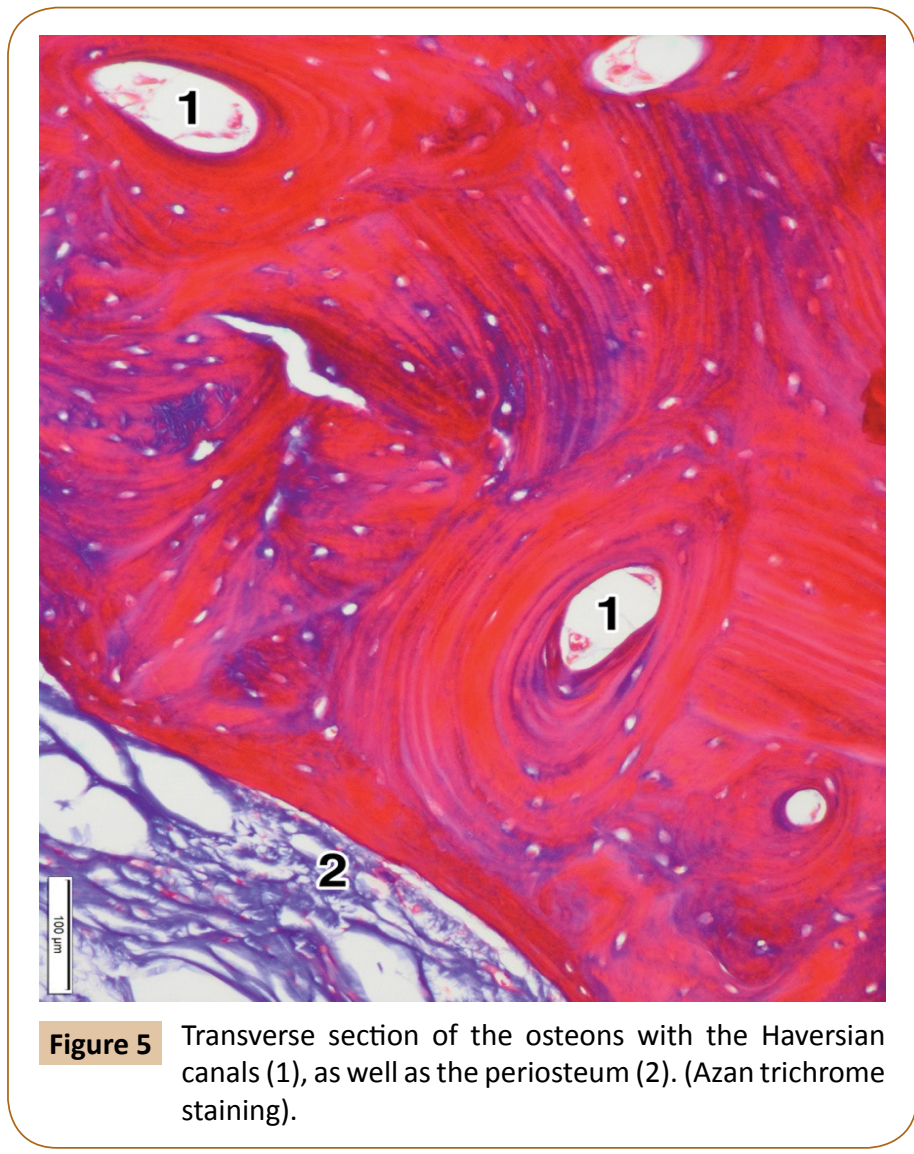

This article is available in: http://orthodontics-endodontics.imedpub.com 
were closed, i.e. they were like small depressions within the outer part of the cortical bone. The remaining pores, however, were open, that is, they continued through the whole thickness of the compact bone, and ended soon in the intertrabecular spaces of the spongy bone (Figure 6). The pores contained small arteries and/or tiny nerves accompanied by just a few collagen fibers or, quite the opposite, by a larger number of the collagen bundles (Figure 6). As regards the typical, long neurovascular canals, they were virtually not observed in the upper part of the alveolar process.

On the other hand, the pores were rarely seen within the lateral part of the palatine process, usually 1 or 2 per a specimen. However, the typical neurovascular canals were present in all the cases (Figure 7). They ranged in number from 3 to 6 (mean, 3.8) at the level of the 1 st and 2 nd premolars. The canals were most often obliquely oriented (Figure 7). After passing through the cortical bone, some of them continued through the spongiosa of the palatine process close to the alveolar process, where they sometimes had a slightly tortuous course (Figure 8). In some cases, the main canal gave rise to one or two smaller side branches when entering the cortical bone. In other instances, each canal divided into 2 or 3 terminal branches (secondary canals) within the compact or the spongy bone.

The openings of the neurovascular canals ranged in size from $90.28 \mu \mathrm{m}$ to $1,230.62 \mu \mathrm{m}$ (mean, $893.62 \mu \mathrm{m}$ ). The initial parts of the canals varied in diameter between $523.42 \mu \mathrm{m}$ and 903.04 $\mu \mathrm{m}$ (622.93 $\mu \mathrm{m}$ on average). Each canal contained a few small

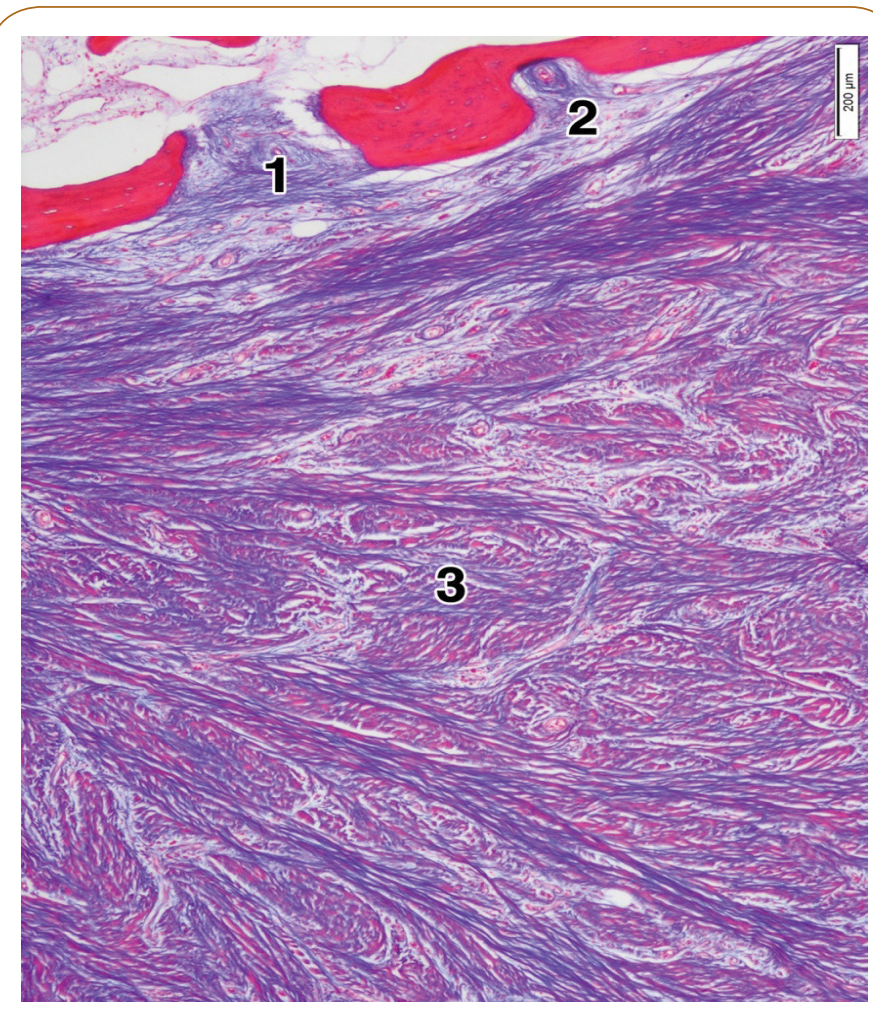

Figure 6 Two pores (1 and 2) of the alveolar process, which contain collagen fibers and small vessels. Note the lamina propria of the gingiva (3). (Azan trichrome staining).

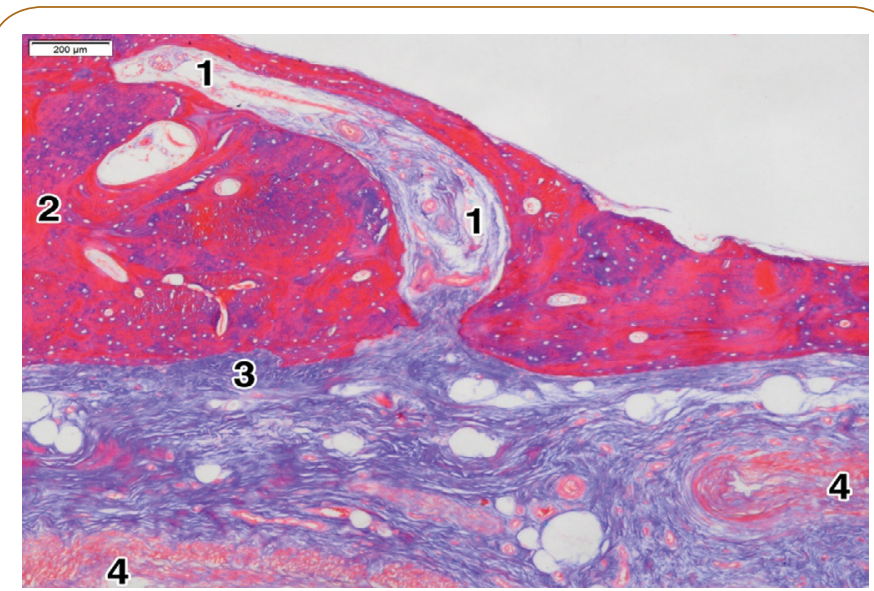

Figure 7 A typical neurovascular canal (1) within the palatine process (2). Note periosteum (3), and branches of the greater palatine artery (4). (Azan trichrome staining).

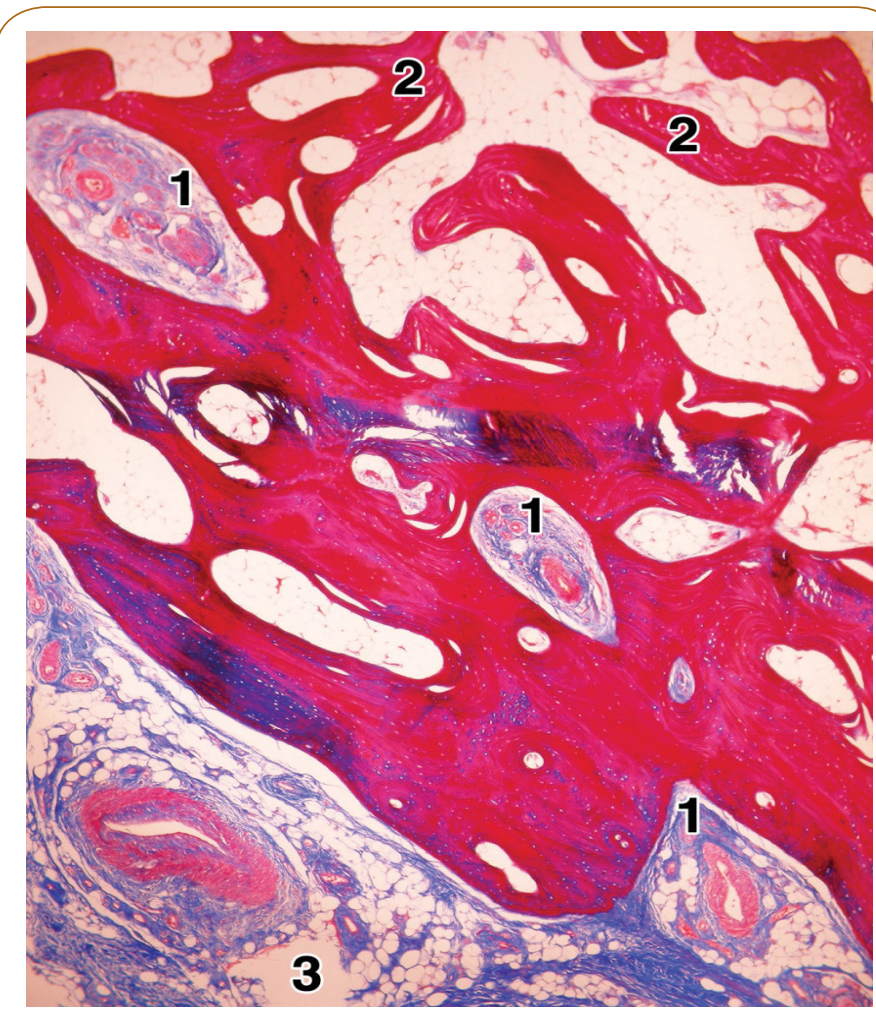

Figure 8 A neurovascular canal (1) with an oblique sinusoid course through the palatine process. Note the spongious bone (2) and the submucous layer (3). ( $\times 4$, Azan trichrome staining).

arteries, or one larger and several smaller arteries, and the veins occasionally. Larger arteries within canals were divided soon into smaller arteries, some of which entered a secondary canal. The nerves represented the twigs of the larger submucosal nerves. There were sporadically small clusters of the fat cells within the canals, as well as certain amount of collagen fibers (Figures 7 and 8).

In order to determine the expression of main type of the collagen, that is, collagen type I, in the bone and surrounding soft tissues, as well as whether those fibers are present in the 


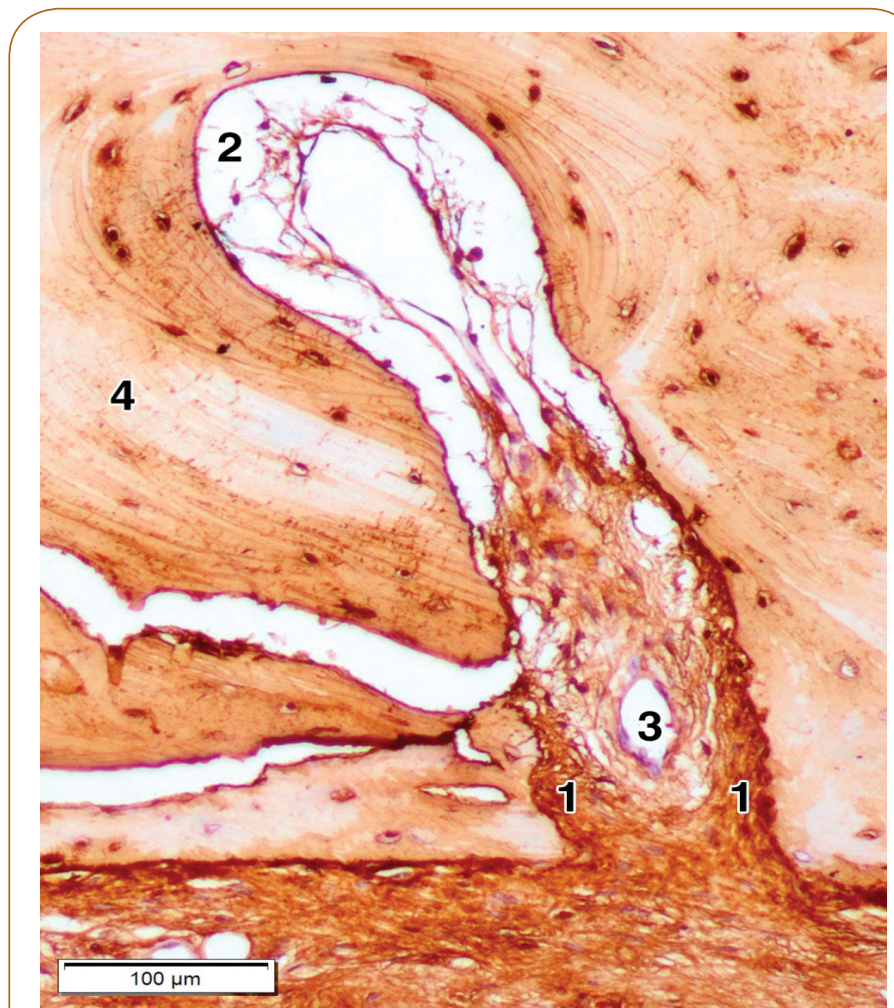

Figure 9 Immunohistochemical reaction against collagen type I. Note a large amount of collagen fibers (1) to enter a neurovascular canal (2) and to surround a small artery (3), as well as compact bone (4) of the palatine process with collagen expression around the osteocytes within decalcified bone matrix. (IHC staining for collagen type I).

neurovascular canals, we performed the IHC examination for collagen type I. The IHC reaction was moderate in the decalcified bone matrix, and very strong in the mucosal lamina propria and the submucous layer, the periosteum, and the neurovascular canals themselves (Figure 9). We also used the IHC for laminin in our specimens, primarily for a better visualization of connective tissue investments of the nerves, and thus the nerves themselves, passing along the neurovascular canal (Figure 10). The strongest laminin IHC reaction was observed in the arterial walls, especially within the adventitial and, partially, the media coat, as well as in the connective tissue investments of the nerves (Figure 10).

The anatomic results will be considered first, and then the histological and IHC findings, as well as the clinical significance of the obtained facts.

\section{Discussion}

\section{Anatomic aspect}

An anesthetic is applied at the level of the 1st and 2nd premolars, close to the greater palatine groove which contains the nerve and the artery of the same name, the branches of which run toward the maxillary anterior teeth $[1,3,8]$. The greater palatine nerve supplies about three quarters of the hard palate $[16,17]$. The accompanying greater palatine artery courses lateral to the nerve [18-20]. Its branches supply the whole hard palate, the mesial part of the alveolar process and, after entering the nasopalatine foramen, the inferior and anterior part of the nasal septum, as well as the anterior portion of the inferior nasal meatus [11].

We examined the bony openings between the greater palatine groove and the mesial part of the alveolar process at the level of the anterior maxillary teeth (Figure 1). There are no reports in literature regarding the number, size and arrangement of the openings. Only Berkovitz [11] mentioned that "The palatine process displays numerous vascular foramina..."

The bony openings observed in our specimens (Figure 1) transmit the twigs of the mentioned greater palatine nerve and artery (Figures 6-10). In addition, we observed in some of our specimens one or several openings between the nasopalatine fossa and the central incisor (Figure 1), which obviously transmits certain nasopalatine nerve twigs. This is in agreement with the finding that the nasopalatine nerve may assist in the innervation of the central incisor, which explains a failure in the anterior superior alveolar nerve block in some patients at this level [11,21], and which is similar to a double innervation of the mandibular incisors $[11,21,22]$.

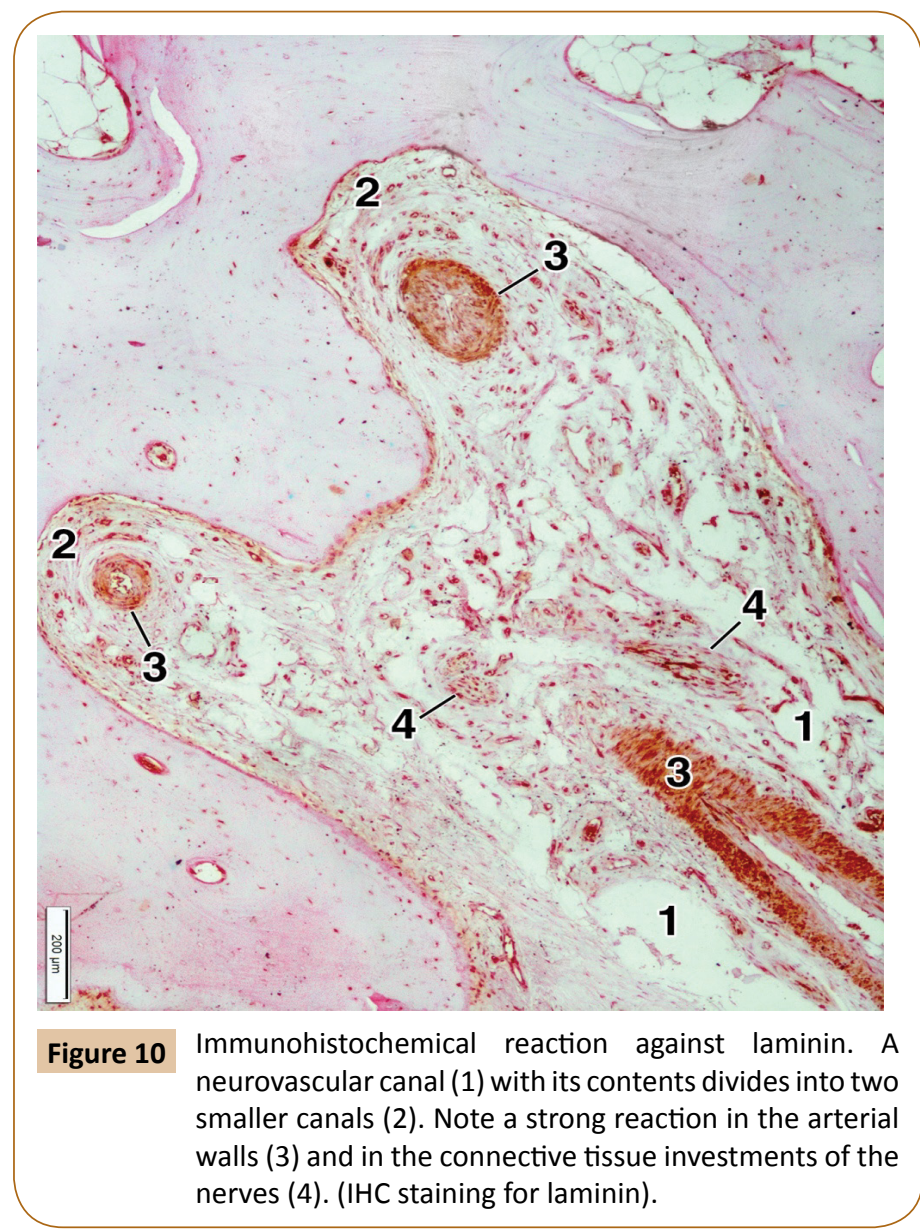


As regards the bony openings themselves, they were observed at the level of each maxillary anterior tooth (Table 1). They were most numerous close to the central and lateral incisors. In addition to these small openings, we noticed in two specimens a large foramen and a canal at the level of the 1st premolar (Figure 1). It seems to be similar to the variable retromolar foramen in the mandible [23-25], which transmits certain neurovascular elements for an additional supply of the mandibular 3rd molar. Such openings and canals in our specimens most likely conduct the neurovascular components as well.

\section{Histological aspect}

The masticatory mucosa comprises the gingiva, as well as the mucous membrane of the hard palate and the upper part of the alveolar process (Figures 3 and 4) [26,27].

The gingiva consists of the squamous ortokeratinized or parakeratinized epithelium and lamina propria, whilst the submucous layer does not exist (Figure 3). The lamina propria contains a dense irregular connective tissue (Figures 3 and 6), i.e. a large number of the collagen I fiber bundles $[11,26]$. Our examination showed that the epithelial lining had a mean value of $0.43 \mathrm{~mm}$ in thickness, whilst the whole mucosa measured about $1.7 \mathrm{~mm}$ on average. Some clinicians take from this site a free gingival graft and apply it around dental implants $[19,28]$. The region of the alveolar process above the gingiva is covered with a mucous membrane (Figure 3).

The palatal mucosa contains the epithelium, lamina propria, and submucous layer [26,29-32]. The whole palatal mucosa (Figure 4) in our specimens averaged $2.87 \mathrm{~mm}$ in thickness at the level of the premolars. Other authors obtained similar or larger values, i.e. $2.25-3.55 \mathrm{~mm}[18,19,31,33,34]$. The differences were due to various sites of measurement, the age of individuals, and the applied techniques: a direct probe, ultrasonic device, computerized tomography (CT), cone-beam CT (CBCT), or histological methods [27,31-35].

The palatal epithelium (Figure4) is also a squamous ortokeratinized or parakeratinized lining, with an averaged thickness of $0.59 \mathrm{~mm}$ in the lateral part of our specimens. According to other authors, the epithelium varied in thickness between $0.31 \mathrm{~mm}$ and 0.38 $\mathrm{mm}$ [29]. Some discrepancies are most likely due to different age of patients and various palatal sites of measurement.

The mentioned lamina propria (Figure 4) consists of the papillary and reticular layers $[26,29,31]$. The papillary layer, connected with the epithelium, comprises high columns (Figure 4) which contain numerous capillary loops. The reticular layer consists of thick bundles of collagen fibers. Yu et al. [31] found out that the thickness of both the epithelium and the lamina propria was 1.28 $\mathrm{mm}$ on average. On the other hand, Cho et al. [29] obtained the average thickness of the lamina propria itself of $1.08 \mathrm{~mm}$ at the level of the 1 st premolar.

Since the lamina propria contains dense collagen bundles and a lot of blood vessels, it is often used as a donor site for autogenous subepithelial connective tissue grafts in periodontal therapy, that is, for a tooth root coverage after soft tissue recession, for the treatment of some mucogingival defects, or for application around dental implants [31,36-40] Some of the mentioned authors histologically confirmed the benefit of such a grafting $[37,38]$.

As noticed in our study and other reports [26,29,31], the submucous layer of the palatal mucosa contains clusters of the fat cells, i.e. adipocytes (Figure 4), minor palatal salivary glands (Figure 2), bundles of collagen fibers, blood vessels, and nerves (Figures 4 and 7). Because of such a composition, this layer is not suitable for grafting in periodontal surgery [32].

The periosteum is a thin connective and vascular layer covering the surface of the cortical bone of the palate and the alveolar process (Figures $\mathbf{4 , 5}$ and $\mathbf{7}$ ). It was connected to the underlying cortical bone by small bundles of the collagen fibers. The periosteum in general contains an outer layer of dense collagen bundles, and an inner layer of the osteoprogenitor cells [26]. We found a larger number of blood vessels within the periosteum, some of which entered the cortical bone via the neurovascular canals.

The periosteum grafts can also be used in oral surgery, for example in the cleft palate repair [41]. Such grafts, due to the presence of the mentioned osteoprogenitor cells, can induce the palatal or alveolar bone regeneration, but also the socket preservation around the dental implants [41-43].

As regards the bone structure of the palatine and alveolar processes, it has already been described by certain authors to some extent, but without any measurement data $[11,26]$. The medial part of the palatine process is mainly formed by the compact bony tissue with the Haversian osteons (Figure 2). The surface of the alveolar process is built by two cortical plates, the lingual (or palatine) and the buccal (or facial) one. However, most of the alveolar process, as well as the lateral part of the palatine process, contained a typical spongy bone with trabeculae and the intertrabecular spaces filled with fat cells, red bone marrow sporadically, and blood vessels and nerves.

\section{Neurovascular canals}

In spite of using several key words in various combinations, we could not find in PubMed any article on the histology of these canals within the palatine or alveolar processes. There are only several articles regarding the canals for the superior alveolar nerves and vessels, including the canalis sinuosus, but only within the walls of the maxillary sinus. They were examined anatomicaly and radiologicaly, and none of them histologically [44-47]. A few other articles were devoted to the vascular alveolar canals of the mandible, including the mentioned variable retromolar foramen and canal, which were examined by $\mathrm{CT}, \mathrm{CBCT}$, or by magnetic resonance imaging (MRI) [23-25].

The pores we found in the alveolar process of the maxilla are actually small neurovascular canals which were, however, much shorter than those within the palatine processes. They usually 
contained a larger number of small arteries, tiny nerves and collagen bundles. They penetrated the cortical bone, entered the spongy bone, and coursed most likely toward the sockets (i.e. dental alveoli) of the maxillary premolars, canine and incisors.

From 1 to 7 of the neurovascular canals were revealed within the palatine process at the level of the 1 st and 2 nd premolars in our specimens. They usually contained a few small arteries (or one larger and several smaller ones), veins occasionally, tiny nerves, certain amount of collagen fibers, and often small clusters of the fat cells. Each canal in serial sections started first as a small depression of the cortical bone, filled with a contents, like a depression of the periosteum and cortical bone. In the subsequent sections, each canal was seen to be formed gradually. It passed first through the cortical (compact) bone, and then obliquely through the spongy bone of the lateral part of the palatine process (Figures $\mathbf{7}$ and $\mathbf{8}$ ). The palatal trabeculae and the intertrabecular spaces communicated with the spongy bone of the superior part of the alveolar process (Figure 2). Some of the canals located medially, i.e. toward the palatal raphe, passed only through the thick cortical bone and obviously supplied only the compact part of the palatine process in that area.

The nutrient canals contained certain vascular and neural twigs which mainly originate from the greater palatine artery and nerve, and sporadically from the nasopalatine nerve $[11,16,21]$. They also house a small number of the adipocytes and certain amount of collagen fibers type I. To our knowledge, the immune reaction against the collagen I has never been performed in this region. It was a similar case with the laminin, which is one of the components of the extracellular matrix and the basal lamina, along with fibronectin, collagen III, and other elements $[15,26]$. The strongest reaction was observed in the arterial walls and the connective investment of the nerves.

As regards the nerves themselves, Russel et al. [48] confirmed the presence of the calcitonin gen-related peptide axons, i.e. the CGRP-positive nerve fibers, within some superior alveolar nerves. These fibers are invovled in nociception, but also in regulation of the adjacent blood vessels [48].

As already mentioned, certain local anesthetic (usually Lidocaine, Mepivacaine, or Articaine) during the AMSA anesthesia is injected into the lateral palate, that is, close to the 1 st and 2 nd premolars [1-4,6-10,13].

The anterior and middle superior alveolar nerves, whose twigs are blocked by the AMSA anesthesia, arise from the infraorbital nerve $[17,49-51]$. The former originates within the infraorbital canal and continues inferiorly along the canalis sinuosus and across the anterior wall of the maxillary sinus. It participates in formation of the anterior part of the superior dental plexus, and innervates the incisors and canine teeth, as well as the surrounding tissues [49]. Its nasal branch supplies the walls of the inferior nasal cavity [17].

The middle superior alveolar nerve, which can be singular, duplicated, triplicated or absent, arise from the infraorbital nerve in its groove, and courses inferiorly and anteriorly across the lateral wall of the maxillary sinus [17]. Its terminal branches, which assist in formation of the mentioned dental plexus, mainly innervate the premolar teeth, and sometimes the mesiobuccal root of the 1st molar $[9,49]$.

As regards the greater palatine nerve $[16,17]$, it leaves the foramen of the same name and continues, together with the greater palatine artery and vein, along the corresponding groove in the lateral palatal region (Figure 1). The branches of the nerve supply the structures of the posterior three quarters of the hard palate, including the palatine process, but also the mesial part of the alveolar process [17]. The rest of the hard palate is innervated by the twigs of the nasopalatine nerve. Since the injection of the anesthetic is very close to the greater palatine groove, great care should be taken during the procedure to avoid a damage to the greater palatine artery and nerve.

The anesthetic is injected, in an amount of less than $2 \mathrm{~mL}$, into the palatine mucosa [9]. Diffusion ability depends, among others, on chemical structure of an anesthetic and the structure of the involved tissue [13]. The injected anesthetic easely diffuses among the collagen bundles of the palatal mucosa (Figures 4 and 7). It can also easely penetrate the membranes and bodies of the present cells, since most of the applied anesthetics are highly liposoluble substances [13].

An anesthetic passes then through the periosteum and along the loose connective tissue within the neurovascular (nutritive) canals of the palatine process, and then continues through the spongy bone in its lateral part (Figures $\mathbf{2}$ and 8). Similarly, the anesthetic also diffuses easily through the pores of the alveolar bone (Figures $\mathbf{3}$ and 6). In this way, the anesthetic blocks first the palatal and alveolar branches of the greater palatine nerve, and then reaches the superior dental plexus where it has the same effect.

\section{Conclusion}

The neurovascular canals with small blood vessels, nerves, collagen fibers, and adipocytes are present in both the alveolar and palatine processes of the maxilla. They most likely represent the histological basis for diffusion of a local anesthetic injected into the lateral palatine region.

\section{Declarations}

Ethics approval and consent to participate.

This study was performed in accordance with the Declaration of Helsinki and carried out with the approval of The Ethics Committee of the Clinical Center of Serbia.

\section{Availability of Data and Materials}

The datasets used and/or analyzed during the current study are available from the corresponding authors on reasonable request.

\section{Authors' Contributions}

The roles of the authors were: DĆ, VT, and SM contributed to the 
conception and design of the study, analysis and interpretation of data.

DĆ, VT, and SM wrote the paper, VT, HH, MO, and JB contributed

\section{References}

1 Acharya AB, Banakar C, Rodrigues SV, Nagpal S, Bhadbhade S, et al. (2010) Anterior middle superior alveolar injection is effective in providing anesthesia extending to the last standing molar in maxillary periodontal surgery. J Periodontol 81: 1174-1179.

2 Corbett IP, Jaber AA, Whitworth JM, Meechan JG (2010) A comparison of the anterior middle superior alveolar nerve block and infraorbital nerve block for anesthesia of maxillary anterior teeth. J Am Dent Assoc 141: 1442-1448.

3 Friedman M, Hochman M (1998) The AMSA injection: A new concept for local anesthesia of maxillary teeth using a computer-controlled injection system. Quintessence Int 29: 297-303.

4 Friedman MJ, Hochman MN (2001) Using AMSA and P-ASA nerve blocks for esthetic restorative dentistry. Gen Dent 49: 506-511.

5 Fukayama H, Yoshikawa F, Kohase H, Umino M, Suzuki N (2003) Efficacy of anterior and middle superior alveolar (AMSA) anesthesia using a new injection system: the Wand. Quintessence Int 34: 537-541.

6 Lee S, Reader A, Nusstein J, Beck M, Weaver J (2004) Anesthetic efficacy of the anterior middle superior alveolar (AMSA) injection. Anesth Prog 51: 80-89.

7 Shirmohammadi A, Faramarzi M, Lafzi A, Kashefimehr A, Malek $S$ (2012) Comparison of pain intensity of anterior middle superior alveolar injection with infiltration anesthetic technique in maxillary periodontal surgery. J Periodon Implant Sci 42: 45-49.

8 Shokraneh A, Farhadi N, Saatchi M, Navaei H, Yaghmaei M (2016) Effect of three different injection sites on the success of anterior middle superior alveolar nerve block with 3\% mepivacaine: A randomized controlled trial. J Contemp Dent Pract 17: 130-135.

9 Tolentino LS, Barbisan Souza AB, Girardi AA, Romito GA, Araújo MG (2015) The anesthetic effect of anterior middle superior alveolar technique (AMSA). Anesth Prog 62: 153-158.

10 Waldman SD (2002) The role of neural blockade in management of common pain syndromes. In: Pain management: a practical guide for clinicians (Weiner RS $6^{\text {th }}$ Edn). Boca Raton, CRC Press, pp: 449-474.

11 Berkovitz BKB (2016) Oral cavity. In: (Standring S Eds) Gray's anatomy. The anatomical basis of clinical practice $\left(41^{\text {st }} \mathrm{Edn}\right)$. London, Elsevier Limited, pp: 507- 533.

12 Fehrenbach MJ, Herring SW (2009) Anatomy of the head and neck $\left(3^{\text {rd }} \mathrm{Edn}\right)$. Saint Louis, Saunders Elsevier.

13 Katzung BG, White PF (2009) Local anesthetics. In: Katzung BG, Masters SB, Trevor AJ (eds) Basic and clinical pharmacology (11 ${ }^{\text {th }}$ Edn). New York, McGraw Hill Medical, Lange, pp: 439-450.

14 Collis GM (2008) Bone. In: Bancroft JD, Gamble M (eds) Theory and practice of histological techniques ( $5^{\text {th }}$ Edn). Philadelphia, Churchill Livingstone, Elsevier, pp: 269-301.

15 Miller KD (2008) Immunocytochemical techniques. In: Bancroft JD, Gamble M (eds) Theory and practice of histological techniques $\left(5^{\text {th }}\right.$ Edn). Philadelphia, Churchill Livingstone, Elsevier, pp: 421-464.

16 Hafeez NS, Ganapathy S, Sondekoppam R, Johnson M, Merrifield P, to the histological examination, and $\mathrm{HH}, \mathrm{MO}$, and $\mathrm{JB}$ have critically read and edited the paper.

All authors have read and approved the final manuscript.

et al. (2015) Anatomical variations of the greater palatine nerve in the greater palatine canal. J Can Dent Assoc 81: 14.

17 Holmes S (2016) Face and scalp. In: Standring S (ed) Gray's anatomy. The anatomical basis of clinical practice $\left(41^{\text {st }} \mathrm{Edn}\right)$. London, Elsevier Limited, pp: 475-506.

18 Kim DH, Won SY, Bae JH, Jung UW, Park DS, et al. (2014) Topography of the greater palatine artery and the palatal vault for various types of periodontal plastic surgery. Clin Anat 27: 578-584.

19 Klosek SK, Rungruang T (2009) Anatomical study of the greater palatine artery and related structures of the palatal vault: considerations for palate as the subepithelial connective tissue graft donor site. Surg Radiol Anat 31: 245-250.

20 Yu SK, Lee MH, Park BS, Jeon YH, Chung YY, et al. (2014) Topographical relationship of the greater palatine artery and the palatal spine. Significance for periodontal surgery. J Clin Periodontol 41: 908-913.

21 Meyer TN, Lemos LL, Nascimento CN, Lellis WR (2007) Effectiveness of nasopalatine nerve block for anesthesia of maxillary central incisors after failure of the anterior superior alveolar nerve block technique. Braz Dent J 18: 69-73.

22 Pereira-Maciel P, Tavares-de-Sousa E, Oliveira-Sales MA (2015) The mandibular incisive canal and its anatomical relationships: $A$ cone beam computed tomography study. Med Oral Patol Oral Cir Bucal 20: 723-728.

23 Capote TS, Gonçalves Mde A, Campos JÁ (2015) Retromolar canal associated with age, side, sex, bifid mandibular canal, and accessory mental foramen in panoramic radiographs of Brazilians. Anat Res Int 2015: 1-8.

24 Muinelo-Lorenzo J, Suárez-Quintanilla JA, Fernández-Alonso A, Marsillas-Rascado S, Suárez-Cunqueiro MM (2014) Descriptive study of the bifid mandibular canals and retromolar foramina: cone beam CT vs panoramic radiography. Dentomaxillofac Radiol 43: 20140090.

25 Sedlacik J, Kutzner D, Khokale A, Schulze D, Fiehler J, et al. (2016) Optimized $14+1$ receive coil array and position system for 3D high-resolution MRI of dental and maxillomandibular structures. Dentomaxillofac Radiol 45: 20150177.

26 Gartner LP, Hiatt JL (2001) Color Textbook of Histology (2 ${ }^{\text {nd }}$ Edn). Philadelphia, W. B. Saunders Company. An Imprint of Elsevier Science.

27 Yaman D, Aksu S, Dişçi R, Demirel K (2014) Thickness of palatal mucosa and its relationship with different parameters in Turkish subjects. Int J Med Sci 11: 1009-1014.

28 Bengazi F, Lang NP, Caroprese M, Urbizo Velez J, Favero V, et al. (2015) Dimensional changes in soft tissues around dental implants following free gingival graftion: an experimental study in dogs. Clin Oral Implants Res 26: 176-182.

29 Cho KH, Yu SK, Lee MH, Lee DS, Kim HJ (2013) Histological assessment of the palatal mucosa and greater palatine artery with reference to subepithelial connective tissue grafting. Anatomy Cell Biol 46: 171-176.

30 Reiser GM, Bruno JF, Mahar PE, Larkin LH (1996) The subepithelial connective tissue graft palatal donor site anatomic considerations for surgeons. Int J Periodontics Restorative Dent 16: 130-137. 
$31 \mathrm{Yu}$ SK, Lee BH, Lee MH, Cho KH, Kim DK, et al. (2013) Histomorphometric analysis of the palatal mucosa associated with periodontal plastic surgery on cadavers. Surg Radiol Anat 35: 463-469.

32 Yu SK, Lee MH, Kim CS, Kim DK, Kim HJ (2014) Thickness of the palatal masticatory mucosa with reference to autogenous grafting: a cadaveric and histologic study. Int J Periodontics Restorative Dent 34: $115-121$.

33 Ramesh KSV, Swetha P, Krishnan V, Mythili R, Rama Krishna A, et al. (2014) Assessment of thickness of palatal masticatory mucosa and maximum graft dimensions at palatal vault associated with age and gender - a clinical study. J Clin Diagn Res 8: ZC09-ZC13.

34 Wara-aswapati N, Pitiphat W, Chandrahpo N, Rattanayatikul C, Karimbux N (2001) Thickness of palatal masticatory mucosa associated with age. J Periodontol 72: 1407-1412.

35 Song JE, Um YJ, Kim CS, Choi SH, Cho KS, et al. (2008) Thickness of posterior palatal masticatory mucosa: the use of computerized tomography. J Periodontol 79: 406-412.

36 Ueno D, Sekiguchi R, Morita M, Jayawardena A, Shinpo S, et al. (2014) Palatal mucosal measurements in a Japanese population using conebeam computed tomography. J Esthet Restor Dent 26: 48-58.

37 Goldstein M, Boyan BD, Cochran DL, Schwartz Z (2001) Human histology of new attachment after root coverage using subepithelial connective tissue graft. J Clin Periodontol 28: 657-662.

38 Majzoub Z, Landi L, Grusovin MG, Cordioli G (2001) Histology of connective tissue graft. A case report. J Periodontol 72: 1607-1615.

39 Monnet-Corti V, Santini A, Glise JM, Fouque-Deruelle C, Dillier FL, et al. (2006) Connective tissue graft for gingival recession treatment: assesment of the maximum graft dimensions at the palatal vault as a donor site. J Periodontol 77: 899-902.

40 Zuhr O, Bäumer D, Hürzeler M (2014) The addition of soft tissue replacement grafts in plastic periodontal and implant surgery: critical elements in design and execution. J Clin Periodontol 41: S123-142.

41 Barutca SA, Aksan T, Uscetin I, Sahin D, Akan M (2014) Effects of palatine bone denudation repair with periosteal graft on maxillary growth: an experimental study in rats. J Craniomaxillofac Surg 42: e1-7.

42 Kermani H, Tabrizi R (2015) Periosteal transposition flap for graft coverage and ridge preservation in the aesthetic zone. J Craniofac Surg 26: 1967-1968.

43 Mouraret S, Von Kaeppler E, Bardet C, Hunter DJ, Chaussain C, et al. (2014) The potential for vertical bone regeneration via maxillary periosteal elevation. J Clin Periodontol 41: 1170-1177.

44 Apostolakis D, Bissoon AK (2014) Radiographic evaluation of the superior alveolar canal: measurements of its diameter and of its position in relation to the maxillary sinus floor: a cone beam computerized tomography study. Clin Oral Impl Res 25: 553-559.

45 Jung J, Yim JH, Kwon YD, Al-Nawas B, Kim GT, et al. (2011) A radiographic study of the position and prevalence of the maxillary arterial endosseous anastomosis using cone beam computed tomography. Int J Oral Maxillofac Implants 26: 1273-1278.

46 Mardinger O, Abba M, Hirshberg A, Schwartz-Arad D (2007) Prevalence, diameter and course of the maxillary intraosseous vascular canal with relation to sinus augmentation procedure: a radiographic study. Int J Oral Maxillofac Surg 36: 735-738.

47 Sato I, Kawai T, Yoshida S, Miwa Y, Imura K, et al (2010) Observing the bony canal structure of the human maxillary sinus in Japanese cadavers using cone beam CT. Okajimas Folia Anat Jpn 87: 123-128.

48 Russel FA, King R, Smillie SJ, Kodji X, Brain SD (2014) Calcitonin generelated peptide: physiology and pathophysiology. Physiol Rev 94: 1099-1142.

49 Yenisey M (2009) Comparison of the pain levels of computer controlled and conventional anesthesia techniques in prosthodontic treatment. J Appl Oral Sci 17: 414-420.

50 Heasman PA (1984) Clinical anatomy of the superior alveolar nerves. Br J Oral Maxillofac Surg 22: 439-447.

51 Somayaji KS, Rao MK (2012) Anatomy and clinical applications of the maxillary nerve in dentistry: a literature review. Dent Update 39: 727-730. 